This item was submitted to Loughborough's Research Repository by the author.

Items in Figshare are protected by copyright, with all rights reserved, unless otherwise indicated.

\title{
Dual screening the political: media events, social media, and citizen engagement
}

\section{PLEASE CITE THE PUBLISHED VERSION}

https://doi.org/10.1111/jcom.12187

\section{PUBLISHER}

Wiley @ International Communication Association

VERSION

AM (Accepted Manuscript)

\section{PUBLISHER STATEMENT}

This work is made available according to the conditions of the Creative Commons Attribution-NonCommercialNoDerivatives 4.0 International (CC BY-NC-ND 4.0) licence. Full details of this licence are available at: https://creativecommons.org/licenses/by-nc-nd/4.0/

\section{LICENCE}

CC BY-NC-ND 4.0

\section{REPOSITORY RECORD}

Vaccari, Cristian, Andrew Chadwick, and Ben O'Loughlin. 2015. "Dual Screening the Political: Media Events, Social Media, and Citizen Engagement”. Loughborough University. https://hdl.handle.net/2134/27427. 


\title{
Dual-Screening the Political: Media Events, Social Media, and Citizen Engagement ${ }^{1}$
}

\author{
Cristian Vaccari, Andrew Chadwick, and Ben O’Loughlin
}

New Political Communication Unit, Royal Holloway, University of London

\begin{abstract}
Dual screening - the complex bundle of practices that involve integrating, and switching across and between, live broadcast media and social media — is now routine for many citizens during important political media events. But do these practices shape political engagement, and if so, why? We devised a unique research design combining a large-scale Twitter dataset and a custom-built panel survey focusing on the broadcast party leaders' debates held during the 2014 European Parliament elections in the United Kingdom. We find that relatively active, "lean-forward" practices, such as commenting live on social media as the debate unfolded, and engaging with conversations via Twitter hashtags, have the strongest and most consistent associations with political engagement.
\end{abstract}

Keywords: Dual screening, political engagement, television, social media, media events, Twitter, hybrid media system

Journal of Communication, 2015

\begin{abstract}
“Author's Accepted Manuscript,” August 20, 2015, for UK Research Excellence Framework eligibility. Please read and cite the final copyedited and typeset version of this article, which can be found here: http://onlinelibrary.wiley.com/journal/10.1111/(ISSN)1460-2466
\end{abstract}

\footnotetext{
${ }^{1}$ We thank Augusto Valeriani, Marco di Felice, Leticia Bode, Kaat Smets, Marta Cantijoch, Amy P. Smith, Kathryn Harnett, and the Social Media and Political Participation Lab at New York University. We also thank Homero Gil de Zúñiga, Victor Garcia-Perdomo, and Shannon C. McGregor for sending us an early draft of their (2015) article.
} 
Citizens' engagement with politics is evolving due to the growing popularity of dual screening: the bundle of practices that involve integrating, and switching across and between, live broadcast media and social media, particularly Facebook and Twitter. Dual screening has become widespread across a range of television genres but it is most significant during what Dayan and Katz (1992) termed "media events": live broadcasts of culturally-resonant, ritualistic, defining moments in the evolution of a national or transnational community (see also Couldry, Hepp, and Krotz (eds.), 2010). Today, the analysis of how audiences experience political media events must incorporate discrete media but also the hybrid articulations and recombinations of media.

Dual screening is an unusual and still emergent set of social practices in which publics combine consumption and commentary during media events, so explaining its significance for political behavior requires methodological innovation. We organized our study around high-profile television- and radio-broadcast UK party leaders' debates during the UK European Parliament elections of 2014. We developed a unique research design that combined: the extraction of a large dataset of political tweets, the identification of a sample of Twitter users whom we recruited to a custom-built, two-wave panel survey, and principal component analysis and multivariate regression analysis of the survey responses. We explain how, why, and to what extent the affordances offered by dual screening, particularly the interactions between broadcast media and Twitter, may, in some ways, reconfigure and promote political engagement. We conceptualize political engagement in three distinct senses - discursive, partisan, and civic — and explain how each of these types is shaped by specific bundles of practices that are possible in a dual screening context.

\section{The Challenge of Researching Dual Screening}

Dual screening is a product of recent changes in media systems: the rapid diffusion and social embedding of digital media, but also the surprising adaptation and renewal of television as a medium. It has quickly become an important bundle of practices in entertainment settings, as commercial market research reveals (Google Think Insights, 2012; Nielsen, 2013). However, it is 
particularly important for understanding totemic political events such as televised candidate debates and high-profile political interviews. These are high-stakes encounters, involving a broadcast media logic-driven sense of anticipation, the discussion of multiple issues and candidate traits in one intensively scrutinized real-time setting, and the emergence of a wide range of possible narratives and interpretations during the event itself. These events are laden with great uncertainty, risk, and drama for politicians, journalists, and publics: the stuff of contemporary democratic politics.

In the context of these complex and rapidly evolving events, today's hyper-accelerated news cycles create greater opportunities for active and strategic intervention, framing, and reframing by a wide array of actors - from elite journalists and campaign staff to committed activists, celebrities, and, of course, lay members of the wider public (Anstead and O'Loughlin, 2011; Chadwick, 2011a, 2011b; Freelon and Karpf, 2015; Kreiss, 2014). While politicians, campaign elites, and professional journalists still exercise significant power, their behavior must now be situated in the context of actors who interface with news-making assemblages as they unfold in real time, using older and newer media logics. The distinctions between the different actor roles proposed by Dayan and Katz (1992) in their analysis of broadcast media events - public actors performing, media actors narrating, and citizens standing by as relatively passive spectators with no direct and public means of intervening in meaning-making-do not fully capture hybrid media events.

Scholarly research on dual screening and politics is in its infancy. As of this writing, only a handful of previously published studies exist, almost all of which draw their conclusions from the content analysis of publicly-available social media data. The first wave of this prior research unearthed a number of relevant findings (Ampofo et al 2011; Anstead and O'Loughlin, 2011; Chadwick, 2011a; Gillespie, O’Loughlin and Proctor, 2013; Jungherr, 2014; Larsson, 2013; Larsson and Moe, 2012). For example, there are identifiable communities of Twitter discourse around the thematic rhythms of a political broadcast media event. Members of the public often play "lay tutelage" roles: they use social media to explain often quite technical points about opinion polling and policy to those less knowledgeable than themselves. Journalists' tweets are significant 
in the structural networks forged by political tweeters, but citizen activists see the value of intervening in real time to shape the narrative frames that they think journalists ought to use to mediate events and that fellow citizens ought to use when learning about the campaign and formulating their opinions. The quantity and quality of information-based user interactions increases substantially during controversial periods in a broadcast. Some users correct, fact check, counter claim, or identify biases in reporting, drawing in an expanding circle of others.

Giglietto and Silva's (2014) analysis of a large dataset of tweets related to political talk shows on Italian television revealed the relationships between the different subgenres in the television text and the levels and styles of Twitter engagement among dual screeners. Lin and colleagues' (2014) study of an even larger (290 million tweet) dataset collected during the 2012 U.S. presidential election campaign found that the unusual conditions of "shared attention" during big news events are associated with reduced levels of interpersonal communication. From a content analysis of the most retweeted tweets during the 2012 U.S. presidential debates, Freelon and Karpf (2015) found that non-elites and what they term "bridging elites" (mainly entertainment celebrities) were just as important in initiating tweets that went viral as were political and journalistic elites.

As should be clear from this brief summary, studies focusing on the content of tweets can offer useful descriptive insights. But such approaches tell us very little about the types of individuals who engage in dual screening practices, and the implications of these practices for subsequent levels and types of political engagement, particularly where engagement may occur away from social media networks, either in other online or face-to-face settings. Exploring these patterns and effects requires that we go beyond the analysis of publicly available social media data to probe the characteristics, motivations, and informational and political behaviors of those who combine watching, reading, posting, and sharing in different ways. There are limits on the amount we can ever know about how individuals experience and respond to media events from content analysis alone, however large (or small) the datasets may be. Inquiry must go beyond the analysis of social media output, such as status updates and network visualizations, to encompass surveys that 
reveal how individuals learn about politics from their dual screening experiences, and the engagement behaviors that may or may not result.

\section{Theorizing Dual Screening}

Our aim in this study is to locate dual screening's position in the complex array of enablers and constraints on individuals' political engagement in a system where interdependencies between older and newer media logics shape political outcomes. We begin from the perspective that dual screening is an essential aspect of hybrid media events: classic broadcast media events whose significance for media professionals, politicians, and non-elites is being reconfigured by the growth of social media (Chadwick, 2011a, 2013; Freelon and Karpf, 2015).

We theorize dual screening as follows: it is a bundle of practices that involve integrating, and switching across and between, broadcast media and social media. For example, individuals may use social media platforms in a relatively passive way to simply read about a broadcast as it unfolds. They may go one step further and comment on social media about a broadcast. They may also be exposed to information about broadcast events on social media in advance of the broadcast and then switch across to the broadcast when it occurs, even in the middle of a show, after which they put their social media screen to one side.

Dual screening blurs the distinction between "lean forward" and "lean back" audience practices. It complicates the relationship between, on the one hand, the relatively active, purposive information-seeking and information-production practices classically associated with computermediated communication, and, on the other hand, the relatively passive, information-reception practices classically associated with broadcast media. In contrast with the media events perspective of Dayan and Katz, today's media environment provides a more complex mix of affordances that may or may not spur engagement. Individuals can choose, to some extent, what to watch, read, post, and share, even though the resources for these behaviors are derived from both social media and mainstream media. In other words, while dual screening blurs the lines between active and passive 
practices, the key point is that several different combinations, or what we term "bundles" of practices are possible.

In using the concept of affordances here we invoke intuitive and established understandings from science and technology studies (Gibson, 1977), the sociology of networks (boyd, 2011; Juris, 2012), and political communication (Chadwick, 2007, 2009). Technological objects — both software and hardware - shape and constrain, though never fully determine human behavior. The living room television screen has historically been a site around which family members and friends gather for communal spectatorship, as Dayan and Katz's (1992) account of media events vividly illustrated. The television's affordances - its relatively large screen and loudspeakers — encourage this. A smartphone is lightweight, comfortable to hold while sitting in an armchair, and has a touch screen interface. These affordances mean that smartphones are more likely to be used for communication and information seeking while watching television than a traditional desktop computer or even a laptop, though they may also be used for simply monitoring the flow of others' commentary—a practice that our approach can reveal. The Twitter hashtag is an affordance of the Twitter platform's design that enables individuals to quickly connect with others and form online political networks. Some of these are fleeting and short lived; others are very persistent (Bennett and Segerberg, 2013).

Explaining precisely what is being reconfigured as these affordances blend in the context of political media events is a significant challenge. Since no extant academic research has untangled the bundle of dual screening practices described above, our first and second research questions are: What types of dual-screening practices around a mediated political event are the most popular? (RQ1) and What are the socio-demographic and relevant political-behavioral characteristics of those who dual screen around a mediated political event? (RQ2).

\section{Theorizing Political Engagement}

Our main focus in this article is on the extent to which the balance of specific media affordances that are mobilized in dual screening contexts may act as drivers of political engagement, both online 
and offline. In the only extant study to use individual survey responses, using a commercial general audience panel survey Gil de Zúñiga and colleagues (2015) examined what they term "second screening." They found that second screening of political television news content is a positive predictor of online political engagement, even after controlling for demographic variables and a number of other correlates, such as trust in media and general patterns of news consumption. In their account, second screening was studied as a general practice among a random sample of the population.

We reconfigure, refine, and extend this line of research. We believe it is important to study dual screening as it emerges around specific political media events. We avoid the term "second screening" because we believe that identifying the hierarchy of screens is a matter for empirical investigation. As we will show, our results reveal that individuals' actual mixing of dual screening practices is more complex and subtle than a "TV first, social media second" approach allows. Our measures identify and disaggregate what it actually means to dual screen, and we model these practices as independent variables that may shape three different types of political engagement, both online and offline. In addition, we designed and deployed our own survey and samples around a specific political media event and the election to which it related. This allows us to base our findings on an authentic high-profile moment of engagement rather than focusing on correlations between generic behaviors measured over arbitrary periods of time.

We theorize our dependent variable—political engagement—in a comparatively rich sense that encompasses the mediated and face-to-face behaviors that occur both during and after a hybrid media event. When building our measures for political engagement, we were keen to identify increases or decreases in both the diversity and the intensity of repertoires of political action, either online or in face-to-face settings, than would otherwise have been the case had an individual not engaged in dual screening practices around the event.

We build upon three distinct empirical understandings in the previous literature on political engagement (Delli Carpini et al., 2004; Heidar, 2006; Putnam et al., 1994). Following Delli Carpini 
et al (2004), we hypothesized that some forms of engagement are discursive - they involve formal and informal conversations about public affairs. Following Heidar (2006), we hypothesized that other forms of behavior are distinctively partisan — these are activities conducted for, or on behalf of, candidates and political parties. Finally, following Putnam et al (1994), we hypothesized that a third dimension of engagement could be identified as civic: behavior that involves collaboration in communities to solve common problems. We therefore ask: Do those who dual screen around a mediated political event become more or less politically engaged as a result of their experience, and how does this differ according to the type of political engagement? (RQ3).

It is possible that many individuals, especially those who are relatively uninterested in politics and who would choose not to watch a broadcast of a political debate or directly follow political actors on social media, might instead encounter information about the debate serendipitously, while using social media for other purposes, such as entertainment or catching up with friends. As we summarized above, media events generate high volumes of discussion on social media. Dualscreening around these events might increase serendipitous exposure, which in turn might contribute to political engagement. Thus, we ask: Are those who are serendipitously exposed to information about a broadcast media event more or less likely to become politically engaged? (RQ4).

Finally, as we argued above, some dual screening practices can be characterized as relatively active, such as commenting on the event or engaging in conversations about it. Others are relatively passive, such as simply watching the event or reading other users' commentary about it. We aim to disentangle the implications for political engagement of these practices by answering our final research question, which brings together and provides an integrated test of our theories about dual screening and political engagement: In the hybrid mix of media affordances and practices involved in the dual screening context around a mediated political event, which have the strongest relationships with political engagement? (RQ5). 
Our method allowed us to stay close to the authentic experiences of individuals as they encountered and responded to what were the biggest scheduled UK political media events between the country's 2010 and 2015 general elections: the controversial April 2014 television and radio debates between deputy prime minister and centrist Liberal Democrat party leader, Nick Clegg, and right-wing UK Independence Party (UKIP) leader and Member of the European Parliament, Nigel Farage.

\section{Research Design and Methods}

Live political debates are the ideal broadcast media events and Twitter is the ideal social media environment to recruit respondents for a project of this kind. According to UK government statistics (2014: 28), by 2013, 22 percent of the British population used Twitter, making it the second most popular social networking site in the UK, after Facebook. Of particular significance for research on dual screening is that 80 percent of UK Twitter users connect to the service through a mobile device and, for 70 percent of those users, mobile access is their primary mode of usage. By 2014, an extraordinary 60 percent of UK Twitter users reported using the service while watching television (Macmillan, 2014).

\section{The \#NickvNigel Debate}

In the run-up to the 2014 European Parliament elections Nick Clegg and Nigel Farage debated twice about Britain's role in Europe (a highly controversial issue in UK politics) - live on the London radio station, $\mathrm{LBC}$, on March 26, and live on the BBC's television channel, BBC2, on April 2. The debates took place before live studio audiences and were hosted by LBC presenter Nick Ferrari and BBC television's David Dimbleby. The television debate was viewed by 1.7 million viewers, a large (nine percent) audience share for that evening (Johnson, 2014; audience figures for the radio debate are unavailable). There was widespread interest in this aspect of the election in the 
United Kingdom, in large part due to UKIP's right-wing, anti-immigration insurgency. The debates were intensely followed and discussed on social media.

\section{Panel Surveys, Sampling, and Measures}

We designed two custom online surveys and administered them in a two-wave panel study. Crosssectional data only provide single point-in-time snapshots and may indicate temporary effects. Panels allow us to identify the sequencing of causal mechanisms and deal with the problem of circularity, or what is sometimes termed endogeneity (Frees, 2004). We were able to measure any change in the dependent variables — political engagement — over time and to model using statistical controls for the value of variables measured at wave 1. Individuals' engagement with politics is usually fairly stable, and the Clegg-Farage debates were self-contained events, so we expected to find that changes in political engagement among our panel respondents would be relatively small and less strongly correlated with dual-screening practices than in the cross-sectional analysis.

Our wave 1 survey ran for the three days immediately following the \#NickvNigel television debate of April 2. Our wave 2 survey ran seven weeks later-during the three days immediately following the day of the UK European Parliament elections. Wave 1 was conducted on a random sample of Twitter users who had posted tweets containing keywords and hashtags related to the debates. Using Twitter's stream application programming interface we collected tweets containing Clegg's and Farage’s names, their Twitter usernames (@Nigel_Farage,@nick_clegg) and keywords and relevant hashtags, such as \#NicvNigel, \#europedebate, \#bbcdebate, and various others, some of which emerged organically during the debates. ${ }^{2}$ Between March 14 and April 3 (one day after the televised debate), we collected about 453,000 tweets that had been posted by more than 103,000 unique users.

\footnotetext{
${ }^{2}$ The full list is: Clegg, Farage, @nick_clegg, @nigel_farage, \#NickvNigel, @LBC, \#EUshowdown, \#LBCfirsteuropedebate, \#LBCdebate, \#whyiamin, \#CleggvFarage, \#bbcqt, \#europedebate, \#cleggvfarage, \#inorout, \#faragefacts, \#teamnigel, \#eurodebate, \#bbcdebate, \#eudebate, Dimbleby.
} 
Through an automated script procedure we used a series of Twitter accounts, whose profile descriptions clearly showed our research purposes, to send invitations to 22,000 unique Twitter users, whom we randomly sampled from the original 103,000, asking them to take our first online survey, which was hosted by Qualtrics. Invitations were sent from April 3 until April 5; responses were collected until April 6. Users in our sample were contacted with a tweet that read as follows: “@[username] University research on social media use: can you help by completing a brief survey?"3

We received 1,634 completed questionnaires in three days -7.5 percent of the 22,000 Twitter users to whom we sent our original invitations. Respondents took, on average, about 15 minutes to complete our questionnaire. Of these 1,634 respondents, 1,187 provided their Twitter name or email address and agreed to be contacted by us in future. This allowed us to survey these respondents again immediately after election day, for wave 2 .

Our wave 2 survey ran from May 23 to May 26, 2014 - the days immediately after the European Parliament election. We received a total of 761 responses. These respondents therefore constitute our two-wave panel, which had a healthy retention rate of 64 percent. Given our unorthodox survey method, which, after all, involved sending unsolicited invitations to complete strangers via Twitter, we consider our response rate at wave 1 and our panel retention rate at wave 2 to be acceptable. We compared our wave 1 and wave 2 respondents and we found no statisticallysignificant differences between them in terms of gender, education, and income (see Table 1 below). Only the mean age of individuals differed: it was slightly higher in wave 2 (41.5) than in wave $1(39.5){ }^{4}$

By focusing on social media users who engaged in dual screening practices around the CleggFarage debates, we were able to identify individuals' socio-demographic and political

\footnotetext{
${ }^{3}$ Ninety-six percent of respondents stated they had received the invitation directly from us. We excluded from our analysis the four percent who responded otherwise. Qualtrics' controls meant the survey could not be answered multiple times from the same computer.

${ }^{4}$ Cramer's Phi coefficient for gender was $-.006(p=.785)$ between Waves 1 and 2 . Chi square coefficient for education was $1.463(p=.833)$ between Waves 1 and 2 . Chi square coefficient for income was $9.491(p=.964)$ between Waves 1 and 2. F coefficient for age was $9.123(p=.003)$ between Waves 1 and 2.
} 
characteristics, sources of political information, and modes of political engagement - variables that would have been impossible to measure by relying solely on the social media content posted by these users. We assessed both mediated and face-to-face behaviors by developing our own survey measures that capture combinations of behaviors that only make sense in a dual screening context, such as: watching or listening to the debates live, reading about and commenting on the debates on social media as the debates were happening, tuning into the debates after reading about them on social media, encountering debate-related information in one's Twitter timeline, engaging with debate-related Twitter hashtags, and searching for debate-related tweets. We included in our questionnaire various measures of political behavior. We asked individuals how likely it was that they would engage in a range of political activities in the coming twelve months.

\section{Modeling}

We conducted a principal component analysis (PCA) on both waves to assess whether and how the different modes of engagement that we measured clustered around the three modes of engagement — discursive, partisan, and civic — that we hypothesized would relate to dual screening practices. On the basis of the PCA, we then constructed three aggregate indices for measuring individuals' engagement in these types of behaviors, which we entered as dependent variables in Ordinary Least Squares (OLS) regression models involving both our cross-sectional and panel data. Due to the exploratory nature of this research, the fact that dual screening is a relatively novel phenomenon, and the fact that most previous studies of social media and engagement are based on cross-sectional data (Boulianne, 2015), in this article we report findings from both the crosssectional and the panel data. We used cross-sectional data to describe a profile of those who dual screened and to provide baseline estimates of the correlations between various modes of dualscreening and the three different modes of political engagement we identified. We then ran the same models with panel data, while controlling for the value of the dependent variables measured at wave 1. 


\section{Findings}

The last row in Table 1 answers our first research question (RQ1) by showing the percentages of respondents who engaged with the different dual-screening activities we measured. Fully seventyone percent of the respondents in our wave 1 sample read about the debates on social media as the debates happened, but only 53 percent watched or listened to the debates live. Forty-eight percent commented on the debates live and 29 percent tuned in to the debates after reading about them on social media. That substantially more respondents read about the debates on social media than watched or listened to them live is somewhat surprising and reveals the media substitution patterns that may emerge when individuals gain their information about a live broadcast event solely by reading about it on social media.

Clearly, the bundle of practices that form the dual screening context were used in different combinations. Some chose not to watch or listen to the debates live but instead learned about them on social media - many in an unplanned, serendipitous way. This is all the more intriguing given that these users received our survey invitation because they had posted keywords related to the debates in advance of the broadcasts. We might expect that a high proportion of our sample would have proceeded to either watch or listen to the broadcast debates live or read about them on social media, or combine the live broadcast with social media in real-time dual screening. It seems that a group of respondents in our sample were keen to post material to Twitter about the debates but not as keen to experience the broadcast debates as they happened. Further research is needed to explore this puzzle in greater detail and here we offer one explanation that we aim to investigate: this behavior may be explained by individuals' desire to introduce their own framings of a broadcast events during the all-important build-up phase, when journalists and politicians are competing to establish the terms on which candidates' debate performances will be judged. Watching a debate or reading about it on social media live as it happens may be seen by some as less important than trying to influence prior perceptions of the debates and the candidates. In other words, this could be 
a consciously chosen way of directing one's time and energy, and thus a form of political engagement in itself.

To answer our second research question - about the characteristics of those who dual screen-we present in Table 1 both cross-section and panel data on sex, age, education, political interest, and attentiveness to the campaign for the respondents who engaged in different dualscreening practices. The distribution of the variables in Table 1 is very similar between the crosssection and panel, which demonstrates the robustness of our data across both waves. To highlight the high levels of education and political interest of our sample, we show statistics for all of our respondents. However, in order to demonstrate that our respondents are in fact similar to those among the UK online population who are politically engaged online, we also present some benchmark data. These are taken from a separate survey we commissioned polling company IPSOS to conduct on a representative sample of the UK online population during May and June 2014. The benchmark column shows data only for respondents who have a Twitter profile and who posted news or political opinions "on social media such as Facebook and Twitter" in the previous twelve months. By comparing the last three columns of the table, we can see striking similarities between our sample and the broader UK online population. In other words, our Twitter sample may be relatively highly educated and interested in politics, but these characteristics are also true of all UK internet users who post about news and politics on social media.

[Table 1 about here]

Table 1 answers RQ2 by revealing that Twitter users who dual-screened the 2014 Clegg-Farage debates were predominantly male and highly educated, though they were drawn from across all age groups. They tended to be very interested in politics. They were also following the European election campaign quite attentively, and such attention grew between waves 1 and 2, as one would expect given the activating effect of a campaign. The profile of this group is consistent with decades 
of research on the correlates of political engagement (Verba, Schlozman, and Brady, 1995), as well as more recent studies on the drivers of political engagement online (see for example Vaccari, 2013). Dual screeners brought their prior political interest to their experience of the Clegg-Farage debates.

To test the relationships between dual screening practices and political engagement (RQs 3, 4, and 5), we used both our cross-sectional data (wave 1) and our panel data (waves 1 and 2). To see if our three types of engagement - discursive, partisan, and civic - were real patterns in the results, we performed a PCA on both the wave 1 and wave 2 data. The results are shown in Table 2. As can be seen from the coefficients, the behaviors we measured divided into three distinctive components. In both waves, out of 13 items, only one- - "using the internet to encourage other people to take political action"-loads on two components rather than one. Moreover, the results are consistent across waves 1 and $2 .^{5}$

[Table 2 about here]

The findings of the PCA confirm that our measures of political engagement are distributed around three main dimensions - discursive, partisan, and civic. Table 2 also shows a great deal of integration between activities that occur online and those that occur in face-to-face settings, which suggests that studies that only focus on online engagement are missing an important set of outcomes from dual screening.

To answer RQs 3, 4, and 5 we used the results of the PCA to construct three indices, one for each of our three types of engagement. Each index includes the values of the variables that the PCA

\footnotetext{
${ }^{5}$ Following established practice, we exclude variables that load with a coefficient of less than .400 . In wave 1, one item - "Encourage someone to vote for a party/candidate via social media" - cross-loaded on both the discursive and partisan indices, but we note that the loading on the discursive index (.408) is much smaller when compared with the loading on the partisan index (.782). We also note that this cross-loading does not occur with the wave 2 data, where the coefficients are .391 and .794 respectively. We therefore decided to include this variable in the partisan engagement index.
} 
showed to be part of the related component across both waves. ${ }^{6}$ Our index of discursive participation thus includes 5 items and ranges from 0 -50 (Cronbach's $\alpha=.836$ wave $1, .775$ wave 2). The index of partisan participation includes 4 items and ranges from $0-40$ (Cronbach's $\alpha=.841$ wave $1, .837$ wave 2), and the index of civic participation includes 3 items and ranges from $0-30$ (Cronbach's $\alpha=.764$ wave $1, .809$ wave 2).

Next, as Table 3 shows, we entered these indices as dependent variables in OLS regression models that included our chosen independent variables measuring the different practices that might constitute dual-screening. We also included as independent variables four measures of how respondents encountered debate information on Twitter: because they saw debate-related messages on their timelines, because they came across a hashtag related to the debates and started following the conversation around it; because someone sent them an "@" mention or a direct message about the debates, and because they purposively searched for commentary on the debates using the Twitter search bar. As Table 3 shows, our models include control variables measuring the frequency of political information acquisition through different media; political attitudes that usually predict political engagement; and socio-demographic characteristics. ${ }^{7}$ We ran these models with both cross-sectional data from wave 1 and panel data from waves 1 and 2.

\section{[Table 3 about here]}

Table 3 shows that political engagement is strongly associated with some of the practices of dual screening around the debates - especially those involving users actively contributing to conversations. It is also associated with some of the Twitter affordances that enable dual screening

\footnotetext{
${ }^{6}$ We did not use component scores because these would be inconsistent across waves 1 and 2 due to the small differences in the coefficients of the PCA, which would have made it problematic to have component scores in wave 1 as predictors of those in wave 2 .

${ }^{7}$ Our income variable had 93 missing values, so rather than introduce bias through listwise deletion, we mean-replaced the missing values and added a dummy variable to the analysis identifying these cases. The coefficients on the dummy variables identifying the missing cases - which are essentially meaningless because they are a function of whatever value one uses to replace the missing observations - are not included in the tables. We thank Josh Tucker for suggesting this technique.
} 
(RQs 3 and 5). This is the case even after controlling for general sources of political information, political attitudes, socio-demographic characteristics and, when using the panel data, previously reported levels of political engagement. In the cross-sectional results at wave 1 we found positive and significant correlations between commenting on the debates via social media and all three types of political engagement - discursive, partisan, and civic. The cross-sectional results also indicate that three specific dual-screening affordances of Twitter are particularly strong predictors of different forms of political engagement. First, seeing debate-related posts in one's own timeline is positively and significantly associated with discursive and partisan engagement. Second, being mentioned by, or receiving direct messages from, other Twitter users is positively and significantly correlated with partisan engagement. Third, encountering debate-related hashtags, which then lead one to read a Twitter conversation about the debates is positively associated with partisan and civic engagement.

However, as the wave 2 columns of Table 3 reveal, most of these correlations do not exist in the wave 2 results. However, some positive and significant correlations are confirmed in wave 2, which suggests that some specific bundles of dual-screening practices and social media affordances did lead to greater political engagement even after applying the more rigorous tests of causality that panel data afford (RQs 3 and 5). In particular, panel respondents who engaged with the CleggFarage debate on Twitter after encountering debate-related hashtags were significantly more likely to engage in discursive and partisan behaviors, whereas those who commented on the debates on social media were significantly more likely to engage in civic behaviors.

As regards the relationship between accidental exposure and engagement (RQ4), in the crosssectional data at wave 1 we found positive and significant correlations between serendipitous exposure to the debates via social media and both discursive and civic engagement. The lack of a correlation between serendipitous exposure and partisan forms of engagement (behaviors aimed at supporting candidates and parties) suggests that serendipitous exposure might be particularly beneficial for engagement because it is more likely to foster broad, nonpartisan forms of behavior 
that are based on discussion and deliberation. We caution however, that in the panel results, the coefficients for both associations remain positive, but are no longer statistically significant.

Our fifth, integrative research question (RQ5) asked which of the hybrid mix of media affordances and practices involved in the dual screening context have the strongest relationships with political engagement. Most of the positive and significant correlations in the cross-sectional data, and all those in the panel data, indicate that when Twitter users were drawn into discussions on the debates by other users - whether because they engaged in live commenting on the events or became part of the "bubbling up" of conversational topics organised around hashtags - these relatively active practices contributed to a statistically-significant increase in individuals' propensity to engage in a range of political activities. This holds even after controlling for people's prior levels of reported engagement and a wide variety of other variables that could conceivably affect these outcomes. In stark contrast, none of the relatively passive forms of dual-screening practices — watching, reading, tuning in, and reading messages in one's timeline — is significantly correlated with engagement in the panel results. To reinforce this point, in the cross-sectional results we also found negative and significant correlations between watching the debates live and civic participation and between reading about the debates live on social media and both partisan and civic participation. Thus, in answer to RQ5, it is the relatively active forms of dual screening practice, which involve individuals contributing commentary and interacting with ongoing conversations, that may lead to the most significant gains in political engagement. The relatively passive and solitary forms of dual screening practice, where users learn about the debates via broadcast media or, indeed, social media, but then fail to become part of the online discussion through the specific affordances of Twitter, are not associated with increases in engagement. Dual screening practices can become influences on political engagement only when they entail some constructive involvement with discussions about a broadcast event, and not when they just function as an additional source of information about it. 
Finally, as we might expect with a sample of politically-interested Twitter users, Table 3 shows that control variables such as the acquisition of political information via websites, social media, and, most notably, face-to-face conversations, interest in politics, and attention to the campaign are all positively and significantly correlated with the three modes of political engagement that we tested. This holds for both cross-sectional and, for the most part, panel results. Intriguingly, at wave 1, acquisition of political information via television was negatively and significantly correlated with all three modes of engagement, though again we stress that these correlations disappear with the panel controls.

\section{Discussion and Conclusion}

Using new research questions, a new combination of methods involving a large sample of individuals, and new findings, we explored user behavior during a high profile, hybrid political media event, and we assessed the implications of this behavior for political engagement. We identified the characteristics of those who engaged in dual screening practices and explained the relationships between dual screening and political engagement in its discursive, partisan, and civic forms, in both online and face-to-face settings.

We found that more respondents read about the debates on social media — many of them by

accident - than watched or listened to them live and that dual-screeners are more likely to be highly educated and highly interested in politics. We showed that respondents' political engagement comprises discursive, partisan, and civic modes and that some dual-screening practices are positively associated with these three modes. This was the case both in the aftermath of the debates, as shown by the cross-sectional results, and several weeks later, as shown by the panel results, though these associations were weaker when we assessed them with panel data, as we expected. We found that accidental exposure to debate-related information on social media was positively associated with discursive and civic engagement when using cross-sectional data, but this association turned out to be short-lived when probed with panel data (RQ4). Finally, we found that, 
within the hybrid mix, commenting on the debates and engaging with conversations via Twitter hashtags were both positively associated with political engagement, while practices entailing reception of information without contributing to the discussion around the debates were negatively associated in the cross-sectional results and made no difference in the panel results (RQ5).

With these results in mind, we can return to our theory that dual screening involves several different combinations or "bundles" of practices and that these practices will have different relationships with political engagement. Recall that these bundles consist either of relatively active, purposive information-seeking and information-production practices, or relatively passive, information-reception practices. Our findings indicate that this distinction has important implications for political engagement: bundles of "lean-forward" practices involving commentary and conversation have the strongest and most consistent associations with different modes of political engagement. Bundles of relatively passive, "lean-back" practices have no effects on political engagement.

Our study extends previous lines of inquiry in several important respects and speaks to several current concerns in the discipline of communication. First, we were able to go beyond the singlemedium approach that has been dominant in previous research on the internet and political engagement (Boulianne, 2009, 2015). Second, not only were we able to identify those who engaged in dual screening practices, we were also able to run a custom two-wave panel survey that contained measures designed to tap the interdependencies among media affordances as they are now experienced by the public. Third, we were able to identify the specific bundles of dual screening practices that correlate positively with engagement.

It is, however, important to recognize that the generalizability of our data is limited by our research design. Due to our desire to get inside a specific hybrid media event we consciously restricted our sample to Twitter users who posted messages containing keywords related to that event before, during, and after the event. We sampled Twitter users on the basis of the keywords they posted, but we cannot describe the general population from which our sample was drawn, and 
thus cannot firmly establish the extent to which our respondents resemble that population. We were able to partly address this problem with our benchmark data from a sample representative of the general UK online population, which, as we pointed out, bears remarkable similarities to our respondent sample (see Table 1). We cannot determine whether our findings can be generalized to those who do not use Twitter or those who do use Twitter but did not post any debate-related keywords. In choosing to study a specific sample of Twitter users to measure behaviors associated with a specific hybrid media event, we consciously prioritized internal validity over external validity. However, we contend that the unrepresentative nature of our sample (when compared with the general population) in some ways reinforces, rather than undermines the significance of our findings. This is because most of our respondents were already politically-engaged, therefore we might reasonably expect that they would not substantially extend their engagement as a result of any particular episode during the course of a campaign, especially when accounting for their previous levels of engagement. The fact that we still found positive and significant correlations between some dual screening practices and different types of political engagement - within an already engaged sample and when analysing panel data—is thus all the more remarkable.

Despite the limits to its generalizability, our analysis shows that, among our sample of Twitter users, dual screening practices extend political engagement and they do so in systemic ways that rest on hybrid articulations between high profile political events, broadcast media coverage, the interactive affordances of social media (particularly Twitter), and specific political behaviors. Since it is through debate-related Twitter hashtags that most of the purposive and accidental and exposure occurs, the affordances of Twitter have a particularly important influence. Thus, the architecture and features of Twitter as a mediated environment interact with broadcast coverage to spur engagement.

The integration of online and face-to-face behaviors as well as the number of individuals experiencing the debate only online and not on television, or both online and on television, indicates how fundamentally hybrid political communication has become at the individual level. 
Communication research that only gathers data on engagement from one medium or one digital application misses the way individuals' political experience is now shaped by combinations of different older and newer media. Surveys can capture this hybridity by incorporating questions about respondents' different modes of information acquisition and political engagement—evidence that is impossible to gather through the content analysis of public "big" data.

More broadly, this requires us to rethink and reconfigure Dayan and Katz's (1992) broadcastera theory of media events. It is now well established that the new affordances of social media, particularly Twitter hashtags, encourage concrete practices of production and active intervention in the flow of broadcast media events, or they may simply make it easier for individuals to monitor a wider range of interpretations of an event (Chadwick, 2011a, 2011b; Freelon and Karpf, 2015; Papacharissi, 2014). Our contribution in this study pushes beyond previous research by operationalizing dual screening empirically, and, moreover, in such a way that reveals patterned relationships between certain types of dual screening practices and certain types of political engagement, among a large sample of individuals. It is not that digital media affordances operate in isolation to create these shifts; rather they function as part of a reconfigured context - the hybrid media event. By articulating broadcast media, social media, and engagement in our empirics, we have been able to demonstrate how today's media events create the ingredients for relatively active, politically-conscious modes of behavior that go beyond the relatively passively-experienced communal rituals that Dayan and Katz once saw as important for consensus and social integration. Hybrid media events are comparatively fertile contexts for political engagement. 


\section{References}

Anstead, N., \& O’Loughlin, B. (2011). The Emerging Viewertariat and BBC Question Time Television Debate and Real-Time Commenting Online. The International Journal of Press/Politics, 16(4), 440-462.

Bennett, W. L. and Segerberg, A. (2013). The Logic of Connective Action: Digital Media and the Personlization of Contentious Politics. New York: Cambridge University Press.

Boulianne, S. (2009). Does Internet Use Affect Engagement? A Meta-Analysis of Research. Political Communication, 26(2), 193-211.

Boulianne, S. (2015). Social Media Use and Participation: a Meta-analysis of Current Research. Information, Communication \& Society, 18(5), 524-538.

boyd, d. (2011). Social Networked Sites as Networked Publics: Affordances, Dynamics, and Implications. In Papacharissi, Z. (ed.) A Networked Self: Identity, Community, and Culture in Social Network Sites (39-58). New York: Routledge.

Chadwick, A. (2007). Digital Network Repertoires and Organizational Hybridity. Political Communication 24(3), 283-301.

Chadwick, A. (2009). Web 2.0: New Challenges for the Study of E-Democracy in an Era of Informational Exuberance. I/S: Journal of Law and Policy for the Information Society, 5(1), 941.

Chadwick A. (2011a) Britain's First Live Televised Party Leaders' Debate: From the News Cycle to the Political Information Cycle. Parliamentary Affairs 64(1), 24-44.

Chadwick A. (2011b) The Political Information Cycle in a Hybrid News System: the British Prime Minister and the "Bullygate" Affair. The International Journal of Press/Politics 16(1), 3-29.

Chadwick, A. (2013) The Hybrid Media System: Politics and Power. New York: Oxford University Press.

Couldry, N., Hepp, A., \& Krotz, F. (Eds.) (2010). Media Events in a Global Age. Abingdon: Routledge. 
Dayan, D. and Katz, E. (1992). Media Events: the Live Broadcasting of History. Cambridge, MA: Harvard University Press.

Delli Carpini M. X., F. Cook and L. Jacobs (2004). Public Deliberation, Discursive Participation, and Citizen Engagement: A Review of the Empirical Literature, in Annual Review of Political Science, 7(1), 315-344.

Freelon, D., \& Karpf, D. (2015). Of Big Birds and Bayonets: Hybrid Twitter Interactivity in the 2012 Presidential Debates. Information, Communication \& Society, 18(4), 390-406.

Frees, E. W. (2004). Longitudinal and Panel Data: Analysis and Applications in the Social Sciences. Cambridge: Cambridge University Press.

Gibson, J. (1977). The Theory of Affordances. In Robert Shaw and John Bransford (Eds.), Perceiving, Acting, and Knowing: Toward an Ecological Psychology (62-82). Hillsdale, NJ: Lawrence Erlbaum Associates.

Giglietto, F. and Silva, D. (2014). Second Screen and Participation: A Content Analysis on a Full Season Dataset of Tweets. Journal of Communication, 64(2), 260-277.

Gil de Zúñiga, H. Garcia-Perdomo, V. and McGregor, S. C. (2015) What Is Second Screening? Exploring Motivations of Second Screen Use and Its Effect on Online Political Participation. Journal of Communication. Online first, July 2015. doi:10.1111/jcom.12174.

Gillespie, M, O'Loughlin, B. and Proctor, R. (2013). Tweeting the Olympics. Confidential report for the BBC World Service, London, 30 March.

Google Think Insights (2012) The New Multiscreen World: Understanding Cross-Platform Consumer Behavior. Google Think Insights Website. Available at http://services.google.com/fh/files/misc/multiscreenworld_final.pdf (accessed January 14, 2014).

Heidar, K. (2006). Party Membership and Participation. In R. Katz, \& W. Crotty (Eds.), Handbook of Party Politics (301-315): London: Sage Publications. 
Johnson, N. (2014). Emmerdale and Corrie outshines BBC's Farage v Clegg debate. Available at http://mediatel.co.uk/newsline/2014/04/03/emmerdale-and-corrie-outshines-bbcs-farrage-vclegg-debate/ (accessed November 5, 2014).

Jungherr, A. (2014). The Logic of Political Coverage on Twitter: Temporal Dynamics and Content. Journal of Communication, 64(2), 239-259.

Juris, J. S. (2012). Reflections on \#Occupy Everywhere: Social Media, Public Space, and Emerging Logics of Aggregation. American Ethnologist, 39(2), 259-279.

Kreiss, D. (2014). Seizing the Moment: The Presidential Campaigns' use of Twitter During the 2012 Electoral Cycle. New Media and Society. Online First. Available at http://nms.sagepub.com/content/early/2014/12/04/1461444814562445.full.pdf+html

Larsson, A. O. (2013). Tweeting the Viewer-Use of Twitter in a Talk Show Context, Journal of Broadcasting and Electronic Media, 57(2), 135-152.

Larsson, A. O. and Moe, H. (2012). Studying Political Microblogging: Twitter Users in the 2010 Swedish Election Campaign, New Media and Society, 14(5), 729-747.

Lin, Y-R, Keegan, B., Margolin, D. \& Lazer, D. (2014). Rising Tides or Rising Stars?: Dynamics of Shared Attention on Twitter during Media Events, PLOS One. Available at http://www.plosone.org/article/info\%3Adoi\%2F10.1371\%2Fjournal.pone.0094093 (accessed October 17, 2014).

Macmillan, G. (2014). 80\% of UK Users Access Twitter via Their Mobile. Twitter Website. Available at: https://blog.twitter.com/en-gb/2014/80-of-uk-users-access-twitter-via-theirmobile (accessed September 12, 2014).

Nielsen (2013) Q1 2013 Cross-Platform Report. Nielsen Website. Available at http://www.nielsen.com/us/en/newswire/2013/action-figures--how-second-screens-aretransforming-tv-viewing.html (accessed January 14, 2014).

OFCOM (2014) Adults’ Media Use and Attitudes Report 2014. London: OFCOM. 
Papacharissi, Z. (2014) Affective Publics: Sentiment, Technology, and Politics. New York: Oxford University Press.

Putnam, R. D., Leonardi, R., \& Nanetti, R. Y. (1994). Making Democracy Work: Civic Traditions in Modern Italy. Princeton: Princeton University press.

Vaccari, C. (2013). Digital Politics in Western Democracies: a Comparative Study. Johns Hopkins University Press.

Verba, S., Schlozman, K. L., \& Brady, H. E. (1995). Voice and Equality: Civic Voluntarism in American Politics (Vol. 4). Cambridge, MA: Harvard University Press. 
Table 1 - Descriptive statistics for our sample and different types of dual-screening during the debates (percentages)

$(\mathrm{C}=$ cross-section, $\mathbf{P}=$ panel)

\begin{tabular}{|c|c|c|c|c|c|c|c|c|c|c|c|c|c|}
\hline & \multicolumn{2}{|c|}{ Watched } & \multicolumn{2}{|c|}{ Read } & \multicolumn{2}{|c|}{ Commented } & \multicolumn{2}{|c|}{ Tuned in } & \multicolumn{2}{|c|}{ Accidentally exposed } & \multicolumn{2}{|c|}{ All sample } & \multirow{2}{*}{$\begin{array}{c}\text { Benchmark } \\
\text { survey }\end{array}$} \\
\hline & $\mathbf{C}$ & $\mathbf{P}$ & $\mathbf{C}$ & $\mathbf{P}$ & $\mathbf{C}$ & $\mathbf{P}$ & $\mathbf{C}$ & $\mathbf{P}$ & $\mathbf{C}$ & $\mathbf{P}$ & $\mathbf{C}$ & $\mathbf{P}$ & \\
\hline Gender: Male & 72 & 69 & 70 & 67 & 72 & 69 & 71 & 67 & 68 & 68 & 69 & 68 & 57 \\
\hline Education (year finished): 15 or younger & 3 & 3 & 3 & 3 & 4 & 4 & 4 & 4 & 3 & 2 & 4 & 3 & 13 \\
\hline 16 & 12 & 11 & 11 & 11 & 11 & 12 & 11 & 12 & 11 & 12 & 11 & 11 & \multirow{3}{*}{23} \\
\hline 17 & 5 & 6 & 5 & 5 & 5 & 4 & 6 & 4 & 5 & 4 & 5 & 5 & \\
\hline 18 & 19 & 18 & 17 & 17 & 20 & 19 & 21 & 20 & 17 & 20 & 16 & 15 & \\
\hline 19 or older & 61 & 62 & 64 & 64 & 60 & 61 & 59 & 60 & 64 & 60 & 65 & 66 & 65 \\
\hline Age: $14-18$ & 9 & 7 & 8 & 6 & 10 & 7 & 14 & 11 & 7 & 6 & 7 & 5 & \multirow{2}{*}{22} \\
\hline $19-24$ & 18 & 16 & 16 & 15 & 18 & 16 & 19 & 17 & 15 & 13 & 14 & 12 & \\
\hline $25-34$ & 17 & 17 & 17 & 16 & 19 & 19 & 17 & 17 & 18 & 17 & 17 & 15 & 38 \\
\hline $35-44$ & 20 & 18 & 24 & 23 & 22 & 21 & 22 & 22 & 25 & 24 & 23 & 23 & 24 \\
\hline $45-54$ & 18 & 24 & 20 & 24 & 18 & 23 & 16 & 21 & 19 & 23 & 21 & 26 & 11 \\
\hline $55-64$ & 13 & 13 & 11 & 12 & 10 & 10 & 11 & 10 & 12 & 13 & 13 & 14 & 2 \\
\hline $65+$ & 5 & 5 & 3 & 4 & 3 & 4 & 2 & 2 & 4 & 4 & 4 & 5 & 2 \\
\hline Interest in politics: Very interested & 75 & 78 & 74 & 78 & 75 & 79 & 75 & 79 & 69 & 74 & 69 & 75 & 59 \\
\hline Moderately & 23 & 21 & 24 & 21 & 22 & 19 & 23 & 20 & 28 & 24 & 26 & 23 & 26 \\
\hline Slightly & 2 & 1 & 2 & 1 & 3 & 2 & 2 & 1 & 3 & 2 & 4 & 2 & 14 \\
\hline Not at all & 0 & 0 & 0 & 0 & 0 & 0 & 0 & 0 & 0 & 0 & 1 & 0 & 1 \\
\hline Follow the campaign: Very closely & 36 & 56 & 30 & 53 & 34 & 58 & 35 & 55 & 25 & 48 & 27 & 48 & 56 \\
\hline Moderately & 45 & 39 & 44 & 40 & 46 & 36 & 45 & 39 & 43 & 41 & 42 & 41 & 35 \\
\hline A bit & 15 & 4 & 19 & 7 & 16 & 5 & 17 & 6 & 24 & 10 & 22 & 10 & 7 \\
\hline Not at all & 4 & 1 & 6 & 0 & 4 & 1 & 3 & 0 & 8 & 1 & 9 & 1 & 2 \\
\hline$\%$ in whole sample & 53 & 54 & 71 & 73 & 48 & 46 & 29 & 27 & 74 & 75 & 100 & 100 & $\mathrm{n} / \mathrm{a}$ \\
\hline$N$ & 872 & 410 & 1153 & 557 & 781 & 349 & 469 & 207 & 1206 & 572 & 1634 & 761 & 199 \\
\hline
\end{tabular}

Note: For both the radio and televised debate we asked: Did you "Watch/listen to the debate live on television/radio?," "Read about the debate on social media as it was happening?," "Comment on the debate on social media as it was happening?," "Tune in to the debate on the radio when you read about it on social media?," "Come across news and information on the debate when you may have gone on social media for a different purpose?" Data in the Benchmark survey column are from an online survey we

commissioned IPSOS to conduct separately between May 29 and June 20, 2014 on a representative sample of UK internet users aged 16-74 (N=1,750). The Benchmark column 
Dual-Screening the Political 28

only shows percentages for respondents who have a Twitter profile and who posted news or political opinions "on social media such as Facebook and Twitter" in the previous twelve months. 
Table 2 - Results of Principal Component Analysis (PCA) of 13 Modes of Political Engagement

\begin{tabular}{|c|c|c|c|c|c|c|}
\hline & \multicolumn{3}{|c|}{ Wave 1} & \multicolumn{3}{|c|}{ Wave 2} \\
\hline & 1 (Discursive) & 2 (Partisan) & 3 (Civic) & 1 (Discursive) & 2 (Partisan) & 3 (Civic) \\
\hline Debate political issues on social media & .857 & .152 & .172 & .839 & .146 & .140 \\
\hline Post political news on social media & .783 & .180 & .251 & .759 & .211 & .249 \\
\hline Comment on a post by a party/candidate on social media & .714 & .312 & .193 & .630 & .395 & .065 \\
\hline Discuss politics with family or friends & .600 & .136 & .128 & .586 & .048 & .249 \\
\hline Debate politics on a forum or blog & .621 & .248 & .249 & .465 & .389 & .222 \\
\hline Use the internet to encourage other people to take political action & .507 & .306 & .483 & .482 & .275 & .541 \\
\hline Encourage someone to vote for a party/candidate via social media & .408 & .782 & .146 & .391 & .794 & .121 \\
\hline Try to convince someone to vote for a party/candidate & .357 & .771 & .044 & .334 & .765 & .133 \\
\hline Encourage someone to vote for a party/candidate by sending an email & .150 & .755 & .278 & .087 & .730 & .352 \\
\hline Give money to a political party & .089 & .714 & .341 & .057 & 679 & .379 \\
\hline Work with a group of people to address a public issue & .238 & .232 & .766 & .222 & .259 & .814 \\
\hline Participate in a protest, rally or demonstration & .174 & .103 & .810 & .161 & .137 & .799 \\
\hline Attend an offline event after receiving an online invitation & .343 & .342 & .635 & .280 & .339 & .690 \\
\hline Eigenvalues & 6.192 & 1.225 & 1.070 & 6.008 & 1.233 & 1.085 \\
\hline$\%$ of variance & 47.62 & 9.42 & 8.23 & 46.21 & 9.48 & 8.34 \\
\hline$N$ & 1495 & & & 748 & & \\
\hline
\end{tabular}

Note: cell entries are component loadings using Varimax rotation. All cases with missing values for half the variables or more in either wave were excluded from the analysis.

Scores in bold font indicate the variables that comprise the discursive, partisan, and civic indices that we took forward to the regressions (see Table 3 ). 
Table 3 - Results of Ordinary Least Squares (OLS) Regressions Predicting Discursive, Partisan, and Civic Engagement

\begin{tabular}{|c|c|c|c|c|c|c|}
\hline & \multicolumn{2}{|c|}{ Discursive } & \multicolumn{2}{|c|}{ Partisan } & \multicolumn{2}{|c|}{ Civic } \\
\hline & Wave 1 & Wave 2 & Wave 1 & Wave 2 & Wave 1 & Wave 2 \\
\hline \multicolumn{7}{|l|}{ Practices of dual-screening during the debates } \\
\hline Watched/listened to the debates live & -1.058 & -.254 & -.355 & -.843 & $-1.627 * *$ & -.705 \\
\hline Read about the debates on social media as the debates happened & -.189 & -.281 & $-3.222 * * *$ & .581 & $-1.430 *$ & -.211 \\
\hline Tuned in after reading about the debates on social media & -.665 & -1.018 & -.216 & -.539 & -.641 & -.718 \\
\hline Commented on the debates on social media as the debates happened & $2.738 * * *$ & .659 & $2.014 *$ & -.076 & $1.185^{*}$ & $1.203 *$ \\
\hline Serendipitously exposed to debate information on social media & $2.306^{* * *}$ & .850 & .396 & -.061 & $1.411 *$ & 233 \\
\hline \multicolumn{7}{|l|}{ Encountering debate information on Twitter } \\
\hline Via posts on timeline & $3.253 * * *$ & .643 & $2.382 * *$ & -.829 & 1.144 & .360 \\
\hline Via mentions (@) & 1.320 & -.149 & $2.395 * *$ & -.244 & .380 & .130 \\
\hline Via hashtags (\#) & 1.014 & $1.355^{* *}$ & $1.580^{*}$ & $1.685^{*}$ & $1.251^{*}$ & .459 \\
\hline Via searching tweets & .256 & -.557 & .833 & -1.427 & .034 & -.546 \\
\hline Dependent variable measured in wave 1 & - & $.571 * * *$ & - & $.712 * * *$ & - & $.717 * * *$ \\
\hline \multicolumn{7}{|l|}{ Sources of political information } \\
\hline Websites & $.878 * * *$ & .385 & .299 & .448 & .293 & $.414^{*}$ \\
\hline Social media & $1.958 * * *$ & $.753 * *$ & $1.284^{* * *}$ & -.095 & $1.097 * * *$ & .171 \\
\hline Newspapers & .021 & .127 & -.165 & -.279 & .220 & .221 \\
\hline Television & $-1.041 * * *$ & .205 & $-.981 * * *$ & .168 & $-1.141 * * *$ & -.223 \\
\hline Radio & $-.602 * *$ & -.217 & -.137 & -.037 & .180 & .327 \\
\hline Face-to-face conversations & $2.202 * * *$ & $.668 * *$ & $1.219 * * *$ & $.846^{*}$ & $1.540 * * *$ & $.893 * * *$ \\
\hline \multicolumn{7}{|l|}{ Political attitudes } \\
\hline Interest in politics & $6.002 * * *$ & $2.064 * * *$ & $4.401 * * *$ & .841 & $3.119 * * *$ & $1.050 *$ \\
\hline Attention to the campaign & $2.388 * * *$ & .699 & $3.130 * * *$ & $1.500 * *$ & $1.712 * * *$ & .261 \\
\hline Trust in British politicians & -.022 & .054 & $.928 * * *$ & .248 & .047 & -.055 \\
\hline
\end{tabular}


Dual-Screening the Political 31

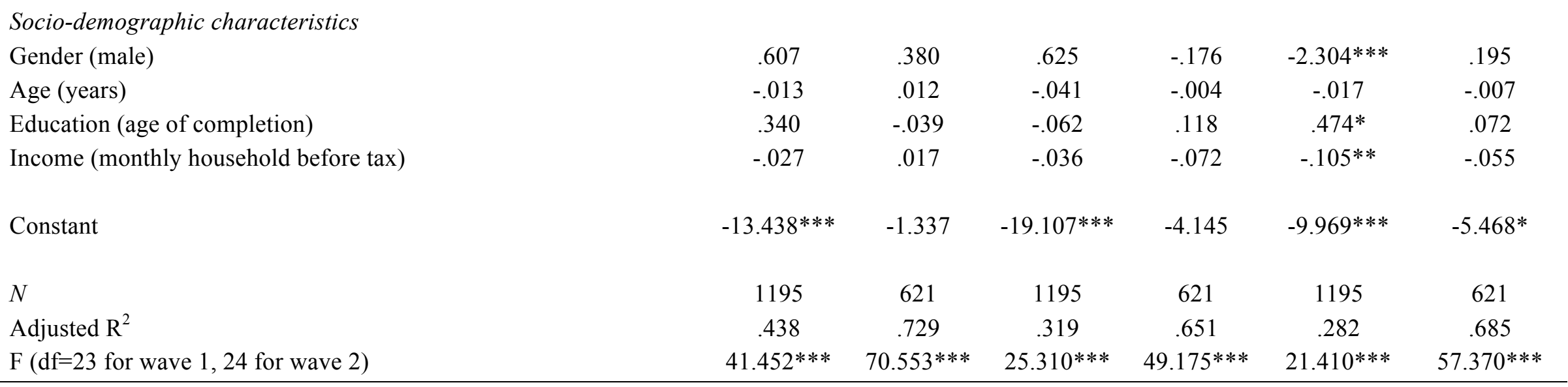

Note: cell entries are unstandardized slope coefficients (B) for the independent variables. ${ }^{* * *} \mathrm{p} \leq .001{ }^{* *} \mathrm{p} \leq .01{ }^{*} \mathrm{p} \leq .05$ 